
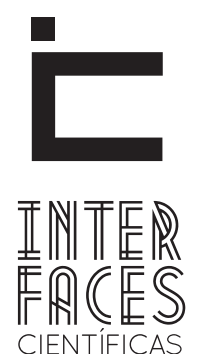

EDUCAÇÃO

ISSN IMPRESSO 2316-333X

E-ISSN 2316-3828

DOI-10.17564/2316-3828.2018v6n3p53-62

NÚMERO TEMÁTICO - PROCESSOS DE FORMACÃÕO ENSINO-APRENDIZAGEM NA CIBERCULTURA

\title{
JORNALISMO COLABORATIVO E CIBERCULTURA: FOTOGRAFIA COMO FONTE DE PERTENCIMENTOEM UMA COMUNIDADE ESCOLAR
}

COLLABORATIVE JOURNALISM AND CYBERCULTURE: PHOTOGRAPHY AS BELONGING OF SCHOOL COMMUNITY

PERIODISMO COLABORATIVO Y CIBERCULTURA: FOTOGRAFÍA COMO PERTENENCIA EN LA COMUNIDAD ESCOLAR

Verusa Pinho

\section{RESUMO}

Na contemporaneidade, as tecnologias da informação e comunicação (TIC), potencializadas pela internet, contribuem para a troca de saberes, ao criar teias de colaboração e relacionamento. Nesse contexto, os canais oficiais das instituições de ensino na rede, especialmente, o Facebook, tornam-se fonte de identidade individual e coletiva, sobretudo se levarmos em consideração o poder das fotografias como elementos de integração dos sujeitos. Ao trazer teorias no diálogo com as práticas cotidianas do Núcleo de Comunicação do Instituto Federal de Educação, Ciência e Tecnologia da Bahia (IFBA) - Campus Seabra, com foco no gerenciamento da rede social supracitada, este artigo se propõe a contribuir com o debate acerca da relação entre Jornalismo Colaborativo e Cibercultura, focando nos registros fotográficos como meios para o sentimento de pertença e o fortalecimento de identidades sociais.

\section{PALAVRAS-CHAVE}

Jornalismo Colaborativo. Cibercultura. Fotografia. Pertencimento. Comunidade Escolar. 


\section{ABSTRACT}

In contemporaneity, Information and Communication technology (ICT), enhanced by the internet, contribute to knowledge exchange, creating collaboration and relationship webs. In this context, the official channels of educational institutions on the web, especially the Facebook, become a source of individual and collective identity, especially if we take into account the power of photographs as elements of integration of subjects. By bringing theories in dialogue with daily practices of Communication Sector of Federal Institute of Education, Science and Technology da Bahia (IFBA) - Cam-

\section{RESUMEN}

En la contemporaneidad, las tecnologías de la información y la comunicación (TICS), potenciadas por Internet, contribuyen al intercambio de saberes, creando redes colaborativas y de relación. En este contexto, los canales oficiales de las instituciones de enseñanza en la red, especialmente, el Facebook, se convierten en fuente de identidad individual y colectiva, sobre todo si llevamos a consideración el poder de las fotografías como elemento de integración de los sujetos. Al establecer diálogos con las prácticas cotidianas del Núcleo de Comunicação do Instituto Federal de Educação, Ciência e Tecnologia da Bahia (IFBA) - Campus Seabra, pus Seabra, focusing in social media management above mentioned, this article aims to contribute to the debate about the relationship between Collaborative Journalism and Cyberculture, aiming on photographic records as a means to the sense of belonging and strengthening social identities.

\section{KEYWORDS}

Collaborative Journalism. Cyberculture. Photography. Belonging; School Community centrado en el quehacer de las redes sociales, este artículo se propone contribuir con el debate sobre las relaciones entre Periodismo Colaborativo y Cibercultura, atendiendo a los registros fotográficos como medio para el sentimiento de pertenencia y al fortalecimiento de las identidades sociales.

\section{PALABRAS CLAVE}

Periodismo Colaborativo. Cibercultura. Fotografía. Pertenencia. Comunidad Escolar. 


\section{INTRODUÇÃO}

As imagens estão presentes em nossas vidas de diversas maneiras. Em casa, na escola, nos meios de comunicação, elas representam uma multiplicidade de sentidos, que, por meio do nosso olhar, dão forma ao mundo que nos rodeia e do qual fazemos parte. $\mathrm{Na}$ contemporaneidade, as tecnologias da informação e comunicação (TIC), potencializadas pela internet, contribuem para a troca de saberes, ao criar teias de colaboração e relacionamento. Nesse contexto, as páginas oficiais das mais diferentes instituições tornam-se fonte de representação de identidades individuais e coletivas, sobretudo quando as imagens são utilizadas como elemento integrador do sujeito; ou seja, amálgama social.

Neste artigo, debruçamo-nos justamente sobre essa questão, ao socializar experiências com base nas práticas cotidianas do setor de Comunicação do Instituto Federal de Educação, Ciência e Tecnologia da Bahia (IFBA), Campus Seabra, com foco no gerenciamento da rede social Facebook. Deste modo, relataremos vivências cibernéticas com o objetivo de compreender a importância das interações visuais - por meio do registro fotográfico, em especial - para a prática do Jornalismo Colaborativo.

\section{JORNALISMO COLABORATIVO \& CIBERCULTURA: A ONDA AGORAÉ COMPARTILHAR!}

Diante das práticas cada vez mais colaborativas proporcionadas pelas tecnologias da informação e comunicação (TIC), principalmente, por meio da web, o Jornalismo Cibernético acompanha a tendência e altera o modelo linear tradicional de conceber o processo de comunicação como emissor-mensagem-receptor. No âmbito das redes sociais, essa realidade é ainda mais evidente, principalmente, por meio do compartilhamento de dados via inbox e comentários. De leitor e fonte de informação ao colaborador na produção de conteúdos noticiosos, os membros de uma comuni- dade escolar, por exemplo, podem se apropriar das peculiaridades da cibercultura, ressignificando ferramentas de modo criativo (ZAGO; RECUERO, 2011). As possibilidades de interação nas redes sociais somam-se aos modismos contemporâneos que tanto atraem, principalmente os jovens e se tornam elementos essenciais na construção e no fortalecimento de identidades. Com o advento da cibercultura, a presença das visualidades torna-se ainda maior em nosso cotidiano. Na opinião de Ribeiro (2016), a escola deve potencializar o uso da web como ferramenta para a formação crítica dos estudantes, visto que eles já a utilizam no dia a dia de maneira autônoma. Citando Manuel Castells (2013), a autora ressalta a importância das redes sociais enquanto plataformas para tipos distintos de atividade, incluindo a educação, classificando-as como espaços "vivos", que modificam a cultura ao compartilhá-la, promovendo interações múltiplas e constantes.

No âmbito dessas plataformas, a troca de dados, com destaque das imagens, tem contribuído para construir e fortalecer identidades sociais. No caso de instituições de ensino, as fanpages oficiais potencializam o compartilhamento de informações, por meio de uma rede colaborativa, alimentada pelos profissionais especializados, responsáveis pelo gerenciamento desses canais, em parceria com os próprios alunos e professores. Os álbuns de fotos, que retratam eventos institucionais, bem como a participação de membros da comunidade em ações externas, são destaques nesse contexto e auxiliam, diretamente, na identificação dos sujeitos enquanto integrantes do espaço escolar, reconfigurando conhecimentos neste novo lócus, que é a rede mundial de computadores.

A internet ${ }^{3}$ e a subsequente emergência do ciberjornalismo proporcionou a exploração de novos territó-

3 Lídia Oliveira Silva (2001) conceitua a internet como um novo espaço público, nova ágora, fórum híbrido (técnico, social e cultural), em que o local (microcosmo) convive com o global em sua dinâmica social; o público com o privado; a pertença com o desenraizamento, o ser produtor com o consumidor de conhecimentos; espaço com o tempo, enquanto frutos de construções sociais partilhadas; informação com contexto de interação/comunicacional. Nessa linha de pensamento, a internet é enfatizada pela autora como o único serviço de telecomunicações que promoveu o estatuto de comunidade para seus utilizadores, mais conhecidos como internautas. 
rios e diferentes linguagens, por meio de narrativas e práticas inéditas (BASTOS, 2012). Dentre outras potencialidades, estão o hipertexto, a interatividade ${ }^{4}$, ubiquidade e instantaneidade. No universo jornalístico, as TIC vieram para ficar, transformando o próprio fazer da profissão à medida que o fenômeno colaborativo cresce (HOLANDA et al., 2008). De meros leitores a coautores da notícia, os cidadãos "leigos” interagem com jornalistas a todo momento, ao sugerir pautas e enviar registros do cotidiano, aprimorando aprendizados por meio das novas mídias.

Sob essa ótica, o posicionamento do jornalista também se torna mais fluido e multifacetado, deixando sua tradicional função de filtrar informações com potencial noticioso (gatekeeping), quando era o centro para onde tudo convergia, e, se tornando, juntamente com o público, um orientador/intermediador, aquele que observa diversos canais de comunicação em busca de conteúdo, ponto de partida de onde novos campos se abrem (gatewatching), criando um jornalismo multiperspectivista, conforme preconiza Bruns (apudidem, ibidem).

Ao conceituar o termo ciberespaço, como o conjunto de redes de telecomunicações criado com o processo digital das informações, Lemos (1996 apud Silva, 2001) ressalta sua relação vital com a cibercultura, relacionando-a ao jornalismo online, como potência geradora de conteúdos informativos que reconfigura o estado de produção e a disseminação da notícia. Segundo o autor (ibidem), a internet seria uma incubadora midiática, na qual impera o engendramento de novas relações, que envolvem o computador como suporte, ferramenta de produção e meio de disseminação ao mesmo tempo.

Para Bruns (2005 apud RECUERO 2009), ao permitir o acréscimo de comentários e novas análises,

40 conceito do termo aqui é entendido de acordo com o pensamento de Vittadini (1995), citado por Mielniczuh (2001), para quem interatividade é a promoção da interação entre pessoas por meio das tecnologias, em especial, do computador. Diante do modelo rizomático das mídias digitais, Castells (1999 apud idem, ibidem) classifica o próprio computador como uma tecnologia interativa. No diálogo com Silva (1997), Mielniczuh aponta a interatividade como o grande paradigma da sociedade da informação, e destaca que, no âmbito do jornalismo digital, a interlocução unidirecional dá lugar à reticularidade, embasando um novo paradigma comunicacional. essas redes envolvem os internautas como produtores das informações, colaboradores do processo noticioso, complementando-o e reconstruindo-o de forma coletiva. A chegada das TIC tem ampliado o horizonte dos profissionais da área de jornalismo, permitindo o uso de uma pluralidade de ferramentas, ao lado da adequação da linguagem ao público e à mídia escolhida. Nesse contexto, as redes sociais, com ênfase no Facebook, têm se tornado uma rica fonte para compartilhamento de conteúdo, devido às facilidades de conversação e replicabilidade.

Difusores de informações, esses canais se caracterizam como verdadeiros filtros colaborativos, produtores e reverberadores de conteúdos, atuando de forma complementar com relação ao jornalismo online (RECUERO, 2009). Em outros trabalhos a autora classifica o "capital social”, dialogando com Bourdieu, para quem a concepção se refere aos recursos que estão relacionados com a associação a uma rede de relações institucionalizadas de conhecimento e reconhecimento mútuo, tendo forte conexão com o grupo que o produz e, por isso, com o sentido de pertencimento. No domínio das redes sociais, tal premissa revela maior mobilização por parte dos sujeitos para se apropriar dos valores concernentes a esse capital (RECUERO, 2007).

Em meio a este "presente compartilhado" (ANDRIJIC, 2013), a atual função social da fotografia pode ser identificada com a de circular o momento captado como desejo de expressão individual, ao mesmo tempo, comunicando e construindo ligações sociais. Diante de motivações distintas para o compartilhamento de dados por parte dos sujeitos envolvidos, que podem oscilar do coletivo ao individual (e vice-versa), no campo das fotografias, até o interesse pessoal na publicação de determinada imagem tende a contribuir com a disseminação dos conteúdos a ela relacionados. “É o 'mostrar e ver' como modo de pertencimento efêmero, tribal, empático que configura uma visão de si e a identificação do outro" (ANDRIJIC, 2013, p. 3), parafraseando Maffesoli, Bauman e Urry.

Segundo Andrijic (2013), essas novas possibilidades ampliam o poder do indivíduo diante da maior sensação de autonomia e segurança. Ao ser possível 
estar sozinho, distante fisicamente, no entanto, próximo de várias pessoas pela conectividade criada a partir dos comentários postados em uma foto publicada no Facebook, estabelece-se uma comunicação, gerando trocas de experiências e opiniões. Nesse sentido, os registros fotográficos podem ser entendidos como mídia de comunicação, ao proporcionar contato entre pessoas (LEMOS, 2007 apud ANDRIJIC, 2013).

Como espaço de sociabilidade ou "socialidade mediada" (THOMPSON, 2002), os media alteram o sentido de pertencimento dos indivíduos. Ao citar McLuhan (1968), Andrijic (2013), lembra que o globo já não é mais do que uma vila, uma verdadeira aldeia global. Considerando o Facebook como uma materialização da teoria, Andrijic apresenta-o como o local de encontro de uma vizinhança virtual, na qual o indivíduo é comunicador e receptor, simultaneamente.

Para apoiar o debate, traremos o exemplo da fanpage do IFBA - Campus Seabra, tecendo comentários a respeito das preferências dos internautas pelos posts que trazem registros fotográficos da própria comunidade escolar. Mas, antes disso, faz-se necessário aprofundar discussões acerca do uso das imagens na educação e seu potencial como fonte de pertencimento e interação.

\section{FOTOGRAFIA \& PERTENCIMENTO: DO INDIVÍDUO AO COLETIVO}

Vivemos e produzimos um novo regime de visualidade, afirma Hernández (2009). Ao ocupar lugar estratégico nos processos de comunicação e nas diversas maneiras de se relacionar dos sujeitos (entre si e com o mundo), as imagens se tornam potenciais fontes de integração. Para Gomes (2013), é perceptível que uma nova roupagem vem sendo dada à produção do conhecimento com ênfase na dialogicidade, fazendo com que a educação formal se aproxime das práticas sociais, valorize as redes conectoras e possibilite, assim, aprendizagens significativas e contextualizadas. Nas palavras do autor, devido a sua natureza plurissignificativa, a cultura visual revela, constrói e problematiza identidades. Como amálgama social, as imagens, além de transmitir informações, têm função religante, especialmente enquanto representação socialmente partilhada de pessoas (com seus sentidos e idiossincrasias) e acontecimentos.

Da identidade à identificação, os media estão no cerne desse processo, contribuindo tanto para a aproximação quanto para o distanciamento dos sujeitos. Como uma ferramenta unificadora, nas palavras de Maffesoli (2000 apud SILVA, 2004), a Comunicação é peça-chave na formação da identidade e imagem de grupos e/ou instituições. No caso dos espaços escolares, diversos por natureza, cabe aos profissionais do referido setor articular valores e símbolos no processo de formação da identidade coletiva $^{5}$, estruturando a produção desses instrumentos para orientar e gerar referências. Nesse contexto, torna-se preciso transpor as barreiras do eu (ego) para o nós (alter), conforme afirma Goergen (2010).

\begin{abstract}
Essa identidade fragmentada implica a inserção dos indivíduos em várias redes de interações. As atenções e as lealdades são divididas em proporções diferentes em cada uma destas redes, o que leva aos seguintes questionamentos: como gerar nas pessoas o sentimento de pertencimento a uma grande rede, obtendo a sua atenção e compromisso como uma causa? Como unir indivíduos com múltiplas identidades e conseguir que eles criem, através do que é comum entre eles, a identidade de um projeto que os unifique? (HALL, 2004, p. 78).
\end{abstract}

Ao fazer uma breve retrospectiva sobre o surgimento da fotografia em meio à revolução tecnológica dos séculos passados, Andrijic (2013) chega ao século XXI e ressalta seu perfil de instantaneidade e automatização, possibilitando, inclusive, a inserção de amadores no processo. Com câmeras cada vez mais compactas e intituivas, ao lado das viabilidades disponíveis nos dispositivos móveis, com destaque para os celulares, em geral, integrados à internet, a produção de imagens se torna mais difusa e acessível.

5 Segundo Thompson (2002, p. 164-165), a "autoidentidade" convive com a "identidade coletiva". Enquanto a primeira está relacionada à trajetória de vida pessoal, a segunda se refere ao sentido de pertença a um grupo que tem história própria e destino coletivo. No entanto, ambas estão carregadas de material simbólico, que se constitui fonte de identidade. 
Para a autora, não há como falar em fotografia digital sem se referir à internet. Ao eternizar momentos, marcar eventos solenes e reforçar a interação com o universo estudantil, por exemplo, as fotos nas fanpages de instituições de ensino, públicas e privadas, da educação básica à profissional, estão diretamente relacionadas ao campo da memória ${ }^{6}$, sendo meio de afeto, emoção, prazer e integração, conforme categorias sociais e psicológicas identificadas por Katz, Gurevitch e Haas (1973 apud ANDRIJIC, 2013).

Por meio desse canal, as comunidades escolares "costuram", diariamente, seu perfil perante a sociedade. É fato que, dentre os posts que mais obtêm sucesso diante dos internautas (maior número de curtidas/ reações, comentários, compartilhamentos e marcações de amigos, levando ao aumento de curtidas e menções da fanpage), estão os registros fotográficos que trazem sujeitos em acontecimentos institucionais ou atividades externas, ao lado de conteúdos de interesse público. Ou seja, as imagens aparecem como elementos de referência na formação de identidades sociais, auxiliando no processo de reconhecimento, pertencimento e corresponsabilidade dos sujeitos enquanto integrantes de uma determinada comunidade.

Andrijic (2013), citando Luiz C. Martino (2003), reforça a relação da fotografia com a rede social Facebook, ao inserir os indivíduos na coletividade: para além dos laços de sangue, o engajamento espontâneo das formas coletivas de agrupamento. Nos tópicos que se seguem, apresentaremos a comunidade escolar IFBA - Campus Seabra, bem como uma análise

\footnotetext{
6 Ao falar da memória, Silva (2001) relaciona sua função à construção de identidades na tridimensionalidade do tempo: passado, presente futuro. Vemos isso no sentimento saudoso dos egressos do IFBA ao visitarem a fanpage e curtirem fotos recentes e/ou antigas, despertando a memória pessoal e coletiva que ainda guardam acerca da instituição e dos laços de amizade que se desenvolveram na e a partir dela. Citando Fentress e Wickham, 1994:8, Silva afirma que nossas recordações pessoais e até o processo cognitivo de recordar contêm na origem muito de social, dando vida a uma relação circular, na qual produzimos técnicas que nos produzem, usam e recriam linguagens, relações, imaginários e racionalidades, resultando em pensamentos que são produtos dos signos e produtor deles mesmos, simultaneamente. Sendo uma construção social que desempenha papel fundamental na própria construção do social, a memória social partilhada é a base da individualidade e suas referências fundadoras (estilos de vida) e se fazem no trabalho relacional, na intersubjetividade, na relação comunitária, especialmente, através dos media interativos reticulares.
}

dos posts mais curtidos em sua fanpage oficial, entre 2015-2016, momento da chegada de uma jornalista à instituição, responsável, dentre outras atividades, pelo gerenciamento desse canal.

\section{INSTITUTO FEDERAL DA BAHIA: UM POUCO DE HISTÓRIA}

O IFBA, criado pela Lei nº 11.892/2008, é resultado das mudanças promovidas no antigo Centro Federal de Educação Tecnológica da Bahia (CEFET-BA). Autarquia do Governo Federal, a instituição existe há mais de 100 anos, estabelecendo-se, em 1910, na capital baiana, com a primeira Escola de Aprendizes Artífices do país. Com a última transformação, o Instituto passou a ter características bem peculiares: equipara-se às universidades federais, atuando com a verticalização do ensino, da educação básica e profissional à superior, além de apresentar estrutura pluricurricular e multicampi.

Hoje o IFBA está em mais de 23 cidades da Bahia, com campis e núcleos avançados, oferecendo cursos de nível médio, nas formas integrada, subsequente e Proeja (educação de jovens e adultos), além de superior, por meio de bacharelados, engenharias, licenciaturas, formações tecnológicas e pós-graduações. Além dos cursos regulares, o Instituto também oferece formação inicial e continuada (FIC), por meio de programas diversos. De acordo com sua filosofia orientadora, a escola é um espaço público de formação social e humanística integrada à técnico-científica.

Nesse sentido, ao lado do ensino, tem-se a pesquisa e a extensão, o que amplia a diversidade de sua atuação e, consequentemente, seus públicos. Deste modo, a identidade do Instituto ainda se encontra em processo de constituição e, até internamente, há dificuldade para estudantes e profissionais compreenderem as mudanças que aconteceram ao longo dos anos e o perfil atual.

No Campus Seabra, situado no Território de Identidade Chapada Diamantina, a realidade é bem peculiar: a maioria do corpo docente é originária de outra 
cidade/estado; quanto aos alunos e técnicos, a supremacia é da zona rural. Inaugurado simbolicamente em Brasília, no ano de 2010, o campus nasce com a segunda fase da expansão da Rede Federal de Educação Profissional, Científica e Tecnológica do Ministério da Educação (MEC) e começa a funcionar provisoriamente em julho de 2011, em um espaço cedido pela Universidade do Estado da Bahia (UNEB). Após quatro anos de existência, o campus conta mais de 400 estudantes matriculados, ao lado de servidores (técnicos administrativos e professores, profissionais concursados) e funcionários terceirizados.

\section{A MAGIA DAS FOTOS NO @INSTITUTOFEDERALDABAHIA.SEABRA: \#EUCURTO}

Com base nesses dados, a inauguração de canais nas redes sociais, com destaque para a fanpage @InstitutoFederaldaBahia.Seabra (criada no fim de 2014), responde a uma demanda da própria comunidade interna, composta, essencialmente, por jovens da geração "Z”, extremamente conectados ao mundo virtual. Apesar da dificuldade de acesso à internet em alguns pontos da região ou da precariedade do sinal, inclusive nos pontos mais centrais das cidades, observa-se a tendência dos estudantes em interagir com os demais integrantes da comunidade IFBA e acompanhar as principais notícias publicadas no site por meio da fanpage oficial.

Ribeiro (2001) apresenta o ciberespaço como novo ambiente de convivências, interações/relações/inter-relações e sociabilidades, em que, através das comunidades virtuais, formam-se vínculos e agrupamentos sociais a partir do grau de afinidades e interesses comuns. Stone (1992), caracteriza o ciberespaço como lugar de desejo intenso de personificação reconfigurada. Baym (1995 apud STONE, 1992) descreve fatores que influenciam diretamente a constituição de processos comunicativos derivados dos espaços virtuais. Dentre eles estão os contextos externos, a infraestru- tura do sistema tecno-informático, os propósitos grupais e as características específicas dos participantes. Segundo o autor, "o conjunto de combinações dessas variáveis promoveria a base para o estabelecimento da dinâmica social emergente da ambiência virtual, criando condições para o florescimento de interações sociais com características peculiares" (BAYM, 1995 apud STONE, 1992, p. 142).

Diante do exposto, ao se veem na fanpage oficial da instituição, alunos e professores, em especial, conectam-se como membros daquela "tribo", como diria Maffesoli (1996 apud STONE, 1992), além de indivíduos/cidadãos dotados de autonomia, também são grupo, situado no contexto de determinada turma, curso, disciplina, projeto..., todos parte de um conjunto maior, que que abrange o IFBA-Seabra, o Instituto como um todo, a Rede Federal de Educação Profissional, Científica e Tecnológica, a classe estudantil e/ ou docente da rede pública de ensino etc., compondo uma rede de ideias e hábitos personalizados.

No caso do IFBA-Campus Seabra, os temas veiculados nesses espaços estão diretamente relacionados às matérias divulgadas no site e enviadas para a imprensa, ações do MEC e de instituições relacionadas ao universo da educação, principalmente da rede Institutos Federais (IF), além de eventos de outros campi e informes da Reitoria, ao lado de cartões de datas comemorativas relacionadas ao universo do Instituto e citação de membros do grupo (sem fotografia, mas, por vezes, acompanhada por um banner com a identidade visual da ação) enquanto participantes de grandes eventos, como as olimpíadas do conhecimento. Posts sobre o Processo Seletivo (modalidade de vestibular dos IF) também estão entre os mais apreciados pelos internautas.

Nesse sentido, a partir da análise de dados oferecidos pelo próprio Facebook, destaca-se a audiência das publicações relacionadas à presença marcante de fotografias. Para exemplificar, tomando como base 0 $2^{\circ}$ semestre de 2016 , tem-se os seguintes álbuns: São João, com 2,9k de alcance; a defesa dos trabalhos de conclusão de curso dos estudantes no ano letivo 2015 (ambos registrados pelo olhar do Núcleo de Comuni- 
cação), com 2,8k, e a participação de alguns jovens, por meio da apresentação de pôster, na $28^{a}$ Reunião da Sociedade Brasileira para o Progresso da Ciência (SBPC), com 2,6k. Vale ressaltar que todas as fotografias deste último evento foram feitas e encaminhadas para a fanpage via inbox pelos próprios alunos, com a descrição do título e da autoria dos trabalhos.

Há também os posts que não geram álbuns, mas são ilustrados com fotos, como a premiação da Olimpíada Brasileira de Matemática das Escolas Públicas (OBMEP), realizada, simbolicamente, em maio de 2016, no próprio campus para a entrega de seis menções honrosas a estudantes, conquistando $3,5 \mathrm{k}$ de alcance, bem como a participação de duas alunas em evento acadêmico no sul do país para socializar pesquisa que deu origem ao Trabalho de Conclusão de Curso (TCC), alcançando a marca de16k, maior até o momento.

No campo dos eventos institucionais, como a "Semana Indígena" e a "Semana Preta", até registros em que aparecem profissionais convidados (externos) incrementam o "ibope" da fanpage, o que se repete nos álbuns sobre visitas de estudantes de outras escolas ao IFBA, contribuindo não apenas com o aumento das curtidas e do alcance dos posts, mas da página em si, que passa a ter fãs de outras instituições, sendo mais conhecida para além dos muros da escola. Tal movimento auxilia no fortalecimento da identidade coletiva, ainda em formação, bem como para a imagem positiva do Instituto perante a sociedade, que inclui pais e responsáveis, egressos, instituições parceiras (empresas, órgãos públicos e sociedade civil organizada), ao lado dos servidores, funcionários terceirizados, estudantes e, esporadicamente, estagiários.

Nesse contexto, a comunidade escolar se vê instigada a fazer seus próprios cliques e enviar para o setor de Comunicação, com o intuito de publicizá- los nos veículos oficiais. Tais imagens, geralmente, ilustram matérias no site, posts e compõem álbuns na fanpage, gerando expectativa por parte dos autores, de seus familiares e amigos. Com base na chamada "audiência participativa" - interação dos internautas nos ambientes digitais, no processo de coleta, sele- ção, edição, produção e publicação de notícias (DEUZE; BRUNS; NEUBERGER, 2007 apud ROCHA; BRAMBILLA, 2009) - o público tem subsídios para construir coletivamente uma narrativa jornalística, configurando-se um "espaço relacional".

Ao potencializar a qualidade da informação, a sociedade em rede permite, ainda, a construção da autonomia individual e coletiva dos sujeitos, que, através das mediações, são capazes de articular memórias, participar, ouvir, falar e serem ouvidos (CARDOSO, 2007 apud STONE, 1992), ou melhor, "verem e serem vistos".

\section{CONSIDERAÇÕES}

No percurso da escrita, chegamos à conclusão de que o potencial participativo das redes sociais e a capacidade de os sujeitos interagirem e compartilharem conteúdos, sobretudo por meio das fotografias, reforçam e contribuem com as práticas do Jornalismo Colaborativo. Assim, as experiências narradas, por meio das práticas cotidianas do Núcleo de Comunicação do Instituto Federal de Educação, Ciência e Tecnologia da Bahia (IFBA) - Campus Seabra, corroboram com a concepção de que imagens são fonte de pertencimento e integração social.

Desse modo, a vivência da referida instituição de ensino pode inspirar tantas outras e, no dia a dia, aperfeiçoar e ampliar relacionamentos, que, em geral, já existem e estão em constante transformação (SULER, 2000 apud RIBEIRO, 2001). Ao ganhar vida, esse movimento promove um novo horizonte para a formação de identidades, com base no conjunto de referências que os sujeitos dividem entre si, em meio aos agrupamentos contemporâneos, guiados pelo prazer de "estar junto" e se emocionar.

\section{REFERÊNCIAS}

ANDRIJIC, Nathalia Santos. Presente Compartilhado: a fotografia nas redes sociais como forma de comunicação e socialização atendendo a 
necessidades. Revista Anagrama/ Revista Científica Interdisciplinar da Graduação, Ano 6, 4.ed., junhoago. 2013.

BASTOS, Helder. A diluição do jornalismo no ciberjornalismo. Estudos em Jornalismo e Mídia, v.9, n.2,'.284-298, julho a dezembro de 2012.

BOURDIEU, Pierre. 0 poder simbólico. 5.ed. Tradução Fernando Tomaz. Rio de Janeiro: Bertrand Brasil, 2002.

GOERGEN, Pedro (Org.). Educação e diálogo. Maringá: Eduem, 2010.

GOMES, Antenor Rita. El uso del cine em prácticas de producción de conocimiento.Revista Educ@rnos, México, ano 3, n.9, p.33-46, abr-jun 2013.

GOMES, A.R.; SILVA, N.O.; GOMES, A.R. Imagem e conhecimento: sentidos moventes, emergências e aprendizagem. Revista de Estudos Universitários, v.39, p.451, 2013.

HALL, Stuart. A identidade cultural na pósmodernidade. 9.ed. Rio de Janeiro: DP\&A, 2004.

HERNÁNDEZ, Fernando. De la alfabetización visual al alfabetismo de la cultura visual. In: MARTINS, Raimundo; TOURINHO, Irene (Org.). Narrativas de ensino e pesquisa na educação da cultura visual, 2009.

HOLANDA, André et al. Metodologias de pesquisa em jornalismo participativo no Brasil, 2008. Disponível em <http://www.sbpjor.org.br/ojs/ include/getdoc. php?id=606\&article $=203 \&$ mode $=p$ df>. Acesso em: 24 out. 2016.

MIELNICZUH, Luciana. Considerações sobre interatividade no contexto das novas mídias. In: LEMOS, André; PALACIOS, Marcos (Org.). As janelas do ciberespaço. Porto Alegre: Sulina, 2001. P.172-185.
RECUERO, Raquel. Redes sociais na internet, difusão de informação e jornalismo:

Elementos para discussão. In: SOSTER, Demétrio de Azeredo; FIRMINO, Fernando (Org.). Metamorfoses jornalísticas 2: a reconfiguração da forma. Santa Cruz do Sul: UNISC, 2009.

RIBEIRO, José Carlos S. Um breve olhar sobre a sociabilidade no ciberespaço. In: LEMOS, André; PALACIOS, Marcos (Org.). As janelas do ciberespaço. Porto Alegre: Sulina, 2001. p.138-150.

\section{RIBEIRO, Josiane da Cruz Lima. Uso do celular} na escola: suas representações e conexões com o ensino e com a aprendizagem. 2016. p.7-16; 5069; 179-186. Dissertação (Mestrado) - Programa de Pós-Graduação em Educação e Diversidade da Universidade do Estado da Bahia - MPED/Uneb, Departamento de Ciências Humanas, Campus IV, Jacobina/BA.

ROCHA, Jorge; BRAMBILLA, Ana Maria.

Comunicação relacional e as mediações possíveis no jornalismo colaborativo, 2009. Disponível em < http://www.rede.bz/wp-content/files/biblioteca/Co municacaorelacionaleasmediacoespossiveisnoJornal ismoColaborativo.pdf>. Acesso em: 24 out. 2016

SILVA JÚNIOR, José Afonso da. Do hipertexto ao algo mais: usos e abusos do conceito de hipermídia pelo jornalismo on-line. In: LEMOS, André; PALACIOS, Marcos (Org.). As janelas do ciberespaço. Porto Alegre: Sulina, 2001. p.126-136.

SILVA, Juremir Machado da. Interfaces: Michael Maffesoli, teórico da comunicação. Disponível em <http://revistas.univerciencia.org/index.php/famecos/ article/view/401/329>. Acesso em: 10 out. 2004

SILVA, Lídia Oliveira. A internet: a geração de um novo espaço antropológico. In: LEMOS, André; PALACIOS, Marcos (Org.). As janelas do ciberespaço. Porto Alegre: Sulina, 2001. p.151-171. 
THOMPSON, John B. A mídia e a modernidade: uma teoria social da mídia. 5.ed. Tradução Wagner de Oliveira Brandão. Petropólis-RJ: Vozes, 2002.
ZAGO, Gabriela e RECUERO, Raquel. Jornalismo em microblogs: um estudo das apropriações jornalísticas do Twitter. In: Jornalismo_contemporâneo:

figurações, impasses e perspectivas, Salvador: EDUFBA; Brasília: Compós, 2011. p.243-266.

Recebido em: 12 de dezembro de 2016

Aprovado em: 16 de outubro de 2017
Recebido em: 3 de Janeiro de 2018

Avaliado em: 1 de Abril de 2018 Aceito em: 4 de Abril de 2018

\begin{abstract}
1 Graduada em Comunicação Social com Habilitação em Jornalismo em Multimeios e Especialista em Ensino da Comunicação - UNEB - Campus III; Integra a equipe de jornalismo do Instituto Federal de Educação, Ciência e Tecnologia da Bahia - IFBA; Aluna regular do Mestrado Profissional em Educação e Diversidade - MPED/UNEB, Jacobina-BA; Membro do Grupo de Pesquisa em Cultura Visual, Educação e Linguagem - CULT-VI. E-mail: verusapinho@gmail.com

2 Professor Titular da Universidade do Estado da Bahia - UNEB/DCH IV; Doutor em Educação - UFBA; Docente do Mestrado Profissional e Educação e Diversidade - MPED/UNEB/DCH IV, Jacobina-BA; Líder do Grupo de Pesquisa em Cultura Visual, Educação e Linguagem - CULTVI. E-mail: argomes@uneb.br
\end{abstract}

